\title{
Comparação da Acurácia de Previsões de Demanda Turística em Sedes Olímpicas
}

\author{
Accuracy of Comparison of Tourism Demand Forecasts in Olympic Hosts \\ Precisión de Comparación de los Pronósticos de la Demanda Turística en Sedes Olímpicas \\ Cristiane Bundchen ${ }^{1}$ \\ Liane Werner ${ }^{2}$
}

\begin{abstract}
Resumo
Boas previsões acerca da demanda turística de um local servem de apoio para corretas tomadas de decisão por parte dos gestores, especialmente quando se tem em vista a realização de um evento de grandes proporções que afeta diretamente no desenvolvimento urbano e econômico locais. Neste estudo, procurou-se compreender o comportamento da demanda turística em frente à realização de um dos maiores megaeventos da atualidade. Para tanto, a demanda turística de dois países que sediaram Jogos Olímpicos foi modelada e prevista através das duas metodologias, uma linear e outra não linear e as previsões obtidas foram combinadas por cinco métodos, sendo três lineares e dois não lineares. Em ambas as séries, as previsões individuais obtidas pelo modelo RNA foram mais acuradas que as geradas pelo modelo SARIMA e as combinações dessas previsões, sobretudo pelo método de regressão linear, aumentaram ainda mais a acurácia das previsões. Ambos os modelos selecionados se mostraram acurados para as previsões de julho de 2012 no Reino Unido e agosto de 2004 na Grécia. Todas as previsões combinadas apresentaram melhor desempenho que a previsão obtida pela modelagem ARIMA, sendo a combinação via regressão linear o método que proporcionou melhor acurácia às previsões. Não foi observado impacto na demanda devido à realização dos Jogos Olímpicos uma vez que o evento ocorreu em um período de alta temporada onde os modelos escolhidos mostraram-se mais precisos.
\end{abstract}

Palavras-chave: Previsão de Demanda; Combinação de Previsões; Megaeventos.

\begin{abstract}
Precise forecasts concerning tourism demand for a certain place serve as support for correct decision making by managers, especially when the realization of a major event directly affecting urban and economic local development is considered. The aim of this study understands the behavior of tourism demand regarding the holding of one of the biggest mega-events of our days. In this regard, the tourism demand of two countries that hosted the Olympic Games was modeled and forecasted using two different methodologies, a linear and a non-linear and the resulting forecasts were combined utilizing five methods - three linear
\end{abstract}

\footnotetext{
${ }^{1}$ Mestre em Engenharia de Produção pela Universidade Federal do Rio Grande do Sul. Porto Alegre, Brasil. Email: crisbundchen@gmail.com

${ }^{2}$ Doutora em Engenharia de Produção pela Universidade Federal do Rio Grande do Sul. Porto Alegre, Brasil. Email: liane@producao.ufrgs.br
} 
and two non-linear. In both series, the individual forecasts obtained by the ANN model were more accurate than the ones generated by the SARIMA model and the combination of these forecasts, especially considering the linear regression method, further increased the precision of the aforementioned combinations. No impact in demand was observed because of the holding of the Olympic Games since the event took place during the high season, when the chosen molds displayed more exactitude.

Keywords: Demand forecast; Forecast combination; Mega-events.

\section{Resumen}

Buenas predicciones acerca de la demanda turística de un lugar sirven de apoyo a la toma de decisiones correctas por parte de los administradores, especialmente cuando tiene que poner en práctica un evento importante que afecta directamente a los sitios de desarrollo urbano y económico. En este estudio, hay tratado de entender el comportamiento de la demanda turística frente a la realización de uno de los mayores magaeventos de hoy. Por lo tanto, la demanda turística de los dos países que fue sede de los Juegos Olímpicos fue modelada y estimada por los dos métodos, lineal y no lineal y las previsiones obtenidas se combinaron para cinco métodos, tres lineales y dos no lineales. En las dos series, las previsiones individuales obtenidas por el modelo ANN fueron más exactas que las previsiones obtenidas por el modelo SARIMA y las combinaciones de estas previsiones, especialmente utilizando el método de regresión lineal, aumentaron aún más la precisión de los pronósticos. Los dos modelos seleccionados demostraron la precisión de las predicciones para julio de 2012 en el Reino Unido y agosto de 2004 en Grecia. Todas las previsiones combinadas superaron lo desempeño de la previsión obtenida mediante la modelación ARIMA, y la combinación mediante el método de regresión lineal proporcionó una mayor precisión de las previsiones. No se observó impacto en la demanda debido a los Juegos Olímpicos debito a que el evento se produjo en un período de temporada alta, donde los modelos elegidos fueron más precisos.

Palabras clave: Previsión de la demanda; Combinación Previsión; Megaeventos.

\section{Introdução}

Megaeventos, tais como Jogos Olímpicos, Copa do Mundo e Jogos Pan-Americanos estão associados a um grande volume de gastos públicos, à construção de instalações e infraestrutura e às estratégias de desenvolvimento e revitalização de áreas públicas que geram ganhos a curto prazo para as partes envolvidas (HALL, 2006). Esses megaeventos esportivos citados podem servir de incentivo para a construção de novas instalações, limpeza e renovação dos espaços das cidades e melhoria da infraestrutura de transportes nos países que os sediam (LONDON ASSEMBLY, 2007). Além dos legados físicos citados, Fourie e Santana-Gallego (2011) também destacam a construção do sentimento de patriotismo ou identidade da nação. 
No levantamento realizado por Fourie e Santana-Gallego (2011) em sedes de megaeventos foi verificado que houve aumento médio de $8,1 \%$ no número de turistas, movimentos significativos de volume de turistas entre os países vizinhos ou que compartilham a língua, moeda ou laços coloniais e, por se tratar de eventos internacionais, aumento de $12,5 \%$ no fluxo de turistas oriundos de países que também participam do evento. Além disso, os autores apontam o efeito da sazonalidade, onde só houve aumentos significativos do número de turistas quando o evento ocorreu no período de baixa-temporada.

Para Goh e Law (2002) a alocação dos recursos suficientes para as operações, comercializações, investimentos e planejamento financeiro por parte dos governantes, ou tomadores de decisão, deve ser embasada em previsões confiáveis e acuradas acerca do volume de turistas. Uma demanda superestimada resultaria no uso ineficiente de recursos e baixos retornos de investimento, ao passo que uma demanda subestimada teria como resultado congestionamentos dos pontos de entrada e atrações turísticas, transporte inadequado, perda de oportunidades de mercado, além da degradação da imagem do país anfitrião (TIDESWELL; MULES; FAULKNER, 2001; STEKLER, 2003).

Ao avaliar o crescimento do campo de pesquisa com relação ao turismo, Tseng, Ma e Chou (2010) constaram o crescente número de artigos voltados para previsão de sua demanda, ratificando a importância desse tipo de análise. Diversos estudos procuraram encontrar o tipo de modelagem mais adequado para prever dados de demanda turística, porém não houve convergência quanto a uma modelagem ideal para todas as situações (SONG; LI, 2008; SONG; HYNDMAN, 2011). Como alternativa Song e Li (2008) sugeriram a utilização da combinação de previsões para melhoria da acurácia.

Segundo Armostrong (2001), o fato de combinar previsões obtidas de técnicas distintas melhora a acurácia das previsões justamente pelo fato de assumir-se que as técnicas individuais de previsão capturam características distintas da série. No âmbito do turismo, Oh e Morzuch (2005) combinaram, através da média aritmética, as previsões geradas por modelos distintos de séries temporais para a demanda de Singapura e concluíram que o desempenho das previsões combinadas foi no mínimo tão acurado quanto o desempenho da pior previsão individual.

Diante da importância de realizar boas previsões, deseja-se compreender o comportamento da demanda turística em frente à realização de um megaevento. A demanda de países que já 
sediaram Jogos Olímpicos de verão foi modelada e prevista até a realização do evento e os desempenhos das previsões foram analisados. As previsões foram estimadas via duas modelagens quantitativas, ARIMA (autorregressive integrated moving average) e RNA (artificial neural networks) e combinadas por cinco métodos: médias aritmética, geométrica e harmônica, variância mínima e regressão linear.

A seção posterior a esta introdução aprofunda os conhecimentos sobre o turismo em megaeventos, bem como detalha as técnicas quantitativas de previsão e combinação de previsões. Os procedimentos metodológicos utilizados para o levantamento dos dados e análises serão descritos na seção correspondente, seguida pela seção que apresentará os principais resultados encontrados. $\mathrm{O}$ artigo se encerra com algumas discussões e conclusões acerca dos achados.

\section{O Turismo de Megaeventos e suas Previsões}

Para Roche (1994), um megaevento pode ser definido por um acontecimento de curta duração, porém de grande escala. Hall (2006) aponta um megaevento envolve grandes volumes de público, gastos do setor público, mercado consumidor, cobertura da mídia, construção de instalações e impacto sobre a economia e a sociedade do anfitrião. Dessa forma, feiras e exposições também poderiam ser incluídas na categoria de megaeventos, porém, no senso comum, os megaeventos estão associados a grandes competições esportivas (TAVARES, 2011). Horne e Manzenreiter (2006) mencionam que esse impacto e exploração de eventos voltados ao esporte foram ampliados com a cobertura televisiva em escala mundial, onde a sua transmissão virou uma rede de negócios (direito de transmissão, patrocínios, etc) e de oportunidades de promoção (legados) para os anfitriões.

Dois legados apontados por Roche (1994) são a imagem e a identidade da nação anfitriã. De acordo com Hall (1992), os megaeventos criam um impacto de crescimento potencial no número de viagens internacionais para o país sede. Para Santovito (2010), os turistas que chegam para acompanhar um evento, acabam retornando em outro momento, além do aumento da chegada de outros turistas após a realização do evento, motivados pelo legado de imagem positiva da nação. Solberg e Preuss (2007) destacam que o período de preparações (pré-evento) também pode gerar atividades consideráveis que acabam repercutindo no turismo. 
Para avaliar o impacto econômico de um megaevento é importe destacar que as estimativas dependem fortemente de contagens precisas dos seus visitantes (CROMPTON, 2010). O autor menciona que muitas vezes o impacto econômico de um megaevento pode ser inflado pelo fato de que aproximadamente um terço dos visitantes contabilizados durante a sua realização veio atraído também por outros recursos do país, de modo que suas despesas seriam geradas independentemente da realização do megaevento.

Além da avaliação do impacto econômico, as previsões precisas de demanda turística servem de suporte para corretas tomadas de decisão por parte dos gestores, como no dimensionamento da capacidade produtiva e gerenciamento da mão-de-obra para o período de realização do megaevento (MOURA; MONTINI, 2010). A realização desses eventos afeta diretamente no desenvolvimento urbano de um local. Segundo Solberg e Preuss (2007) o país que pretende sediar este tipo de evento com o intuito de melhorar a sua atratividade como destino turístico deve analisar o desenvolvimento urbano sob três perspectivas: (i) o desenvolvimento planejado para a cidade independentemente da realização do evento; (ii) a infraestrutura demandada pelo evento que está inclusa no plano de desenvolvimento da cidade e (iii) a infraestrutura específica para o evento que não faz parte do planejamento inicial.

Visando dar suporte a implementação de ações que promovam o desenvolvimento urbano, faz-se necessário dimensionar adequadamente a demanda para suprir as necessidades para que ocorra tal desenvolvimento. Segundo a meta-análise sobre previsão de demanda turística internacional realizada por Peng, Song e Crouch (2014), as três categorias principais de métodos quantitativos de previsão são: modelos de séries temporais, os modelos econométricos e os de inteligência artificial. No levantamento realizado pelos autores, entre os modelos de séries temporais, os mais utilizados para previsão de demanda voltada ao turismo foram os propostos inicialmente por Box e Jenkins e entre os métodos de inteligência artificial estavam os modelos RNA.

\section{Técnicas de Previsão}

\section{1 Metodologia de Box-Jenkins}

A análise de uma série temporal é o procedimento de descrever o processo gerador da série através da identificação dos seus padrões, características e propriedades importantes, sendo o maior objetivo a geração de modelos voltados à previsão de observações futuras 
(GOLDSCHMIDT; PASSOS, 2005). Entre as metodologias criadas para analisar uma série de tempo, os modelos de Box-Jenkins ou ARIMA, desenvolvidos na década de 70, até hoje são os modelos mais divulgados e utilizados. Esses modelos são classificados como estacionários, pois são baseados na hipótese de que o processo permanece em equilíbrio em torno de um nível médio que se mantem com uma variação pequena ao logo do tempo (MORETTIN; TOLOI, 2006).

Diversos modelos ARIMA podem ser utilizados para modelar uma série temporal de acordo com as suas características, sendo que os modelos podem ter apenas componentes autoregressivos (AR), componentes de média móvel (MA) e ambos componentes (ARMA). Além disso, séries não estacionárias podem ser modeladas através de modelos ARIMA, onde são realizadas diferenças com o intuito de tornar a série estacionária, e séries com componente sazonal são modeladas através de modelos denominados SARIMA. Pai et al (2010) comentam que tendo em vista a presença de sazonalidade nos dados de previsão voltados para a demanda turística, este último modelo acaba sendo mais amplamente utilizado.

O modelo $\operatorname{SARIMA}(p, d, q)(P, D, Q)_{\mathrm{s}}$ é definido conforme a Equação 1.

$$
\phi(B) \Phi_{P}\left(B^{s}\right) \Delta^{d} \Delta_{s}^{D} Z_{t}=\theta(B) \Theta_{Q}\left(B^{s}\right) \varepsilon_{t}
$$

Equação 1

Onde $\phi(B)$ é o operador autorregressivo (AR) de ordem $p ; \theta(B)$ é o operador médias móveis (MA) de ordem $q$; $\Phi_{P}$ é o operador AR sazonal de ordem $P$; $\Theta_{Q}$ é o operador MA sazonal de ordem $Q ; \Delta^{d}$ é o operador diferença não sazonal; $\Delta_{s}^{D}$ é o operador diferença sazonal de ordem s, s é o período sazonal e $\varepsilon_{t}$ é um ruído branco.

\subsection{Redes Neurais Artificiais (RNA)}

Uma RNA tenta capturar a informação ou conhecimento através de aprendizado de forma similar ao cérebro humano. As unidades de processamento simples (neurônios) que compõem uma RNA são adaptáveis ao ambiente através de interligações (sinapses). Nestas interligações é onde ocorre o processo de aprendizagem por meio de conhecimento experimental adquirido que fica armazenado e disponível para uso (HAYKIN, 2001).

De acordo com Zhang, Patuwo e Hu (1998), esse tipo de modelagem apresenta três características particulares: (i) diferentemente dos métodos tradicionais, as RNAs são métodos auto-adaptativos em que há poucas suposições acerca as características dos dados analisados, 
podendo ser interpretadas como um método não linear não paramétrico; (ii) possuem capacidade de generalização pois aprendem com os dados; (iii) conseguem aproximar qualquer função contínua que tente explicar a relação entre entradas e saídas a qualquer precisão desejada. Entre os diversos tipos de modelos de RNA, o perceptron multicamadas (MLP, multilayer perceptron) é o tipo de rede feedforward mais amplamente utilizada com o intuito de realizar previsões voltadas ao turismo (KON; TURNER, 2005; CLAVERIA; TORRA, 2014).

Uma rede MLP é tipicamente composta por camadas que contém neurônios, sendo a primeira camada uma entrada onde são recebidas informações externas e a última camada é uma saída com a solução obtida. Entre estas camadas estão as camadas intermediárias ou ocultas. Segundo Braga, Carvalho e Ludermir (2000), o poder computacional desse tipo de rede com múltiplas camadas é muito superior ao das redes sem elas. As camadas interna e externa são fixas, pois são construídas de acordo com a entrada e saída desejadas, já as camadas ocultas e o algoritmo de treino são ajustáveis de modo a maximizar o desempenho da rede. Dessa forma, podem-se obter modelos exploratórios ou causais equivalentes a um modelo de regressão não linear ou modelos de séries temporais não lineares (ZHANG; PATUWO; HU, 1998).

O algoritmo mais utilizado para a fase de treino (aprendizagem) de uma rede é o algoritmo de retropropagação do erro. Neste algoritmo, o treinamento ocorre em duas fases de sentidos opostos, para frente e para trás. No processamento para frente o sinal de entrada parte da primeira camada e vai de camada em camada (quando há mais de uma camada oculta) até a camada de saída, onde se transforma no resultado da rede (sinal de saída). Na fase para trás, esse sinal de saída é comparado a uma resposta verdadeira e o erro gerado pela diferença entre as duas respostas segue caminho inverso do sinal de entrada de modo a reajustar os pesos sinápticos minimizando este erro (BRAGA; CARVALHO; LUDERMIR, 2000).

A limitação do modelo MLP é que a saída é um modelo não linear resultante de várias combinações lineares das variáveis de entrada, portanto contém muitos parâmetros que são não interpretáveis (KUTNER et al, 2005).

\subsection{Métodos de combinações de previsões}

Com o intuito de melhorar a acurácia das previsões, uma estratégia utilizada com frequência é a de combinar as previsões dos modelos individuais através de algum método (CONSTANTINE; PAPPALARDO, 2010). Essa estratégia foi desenvolvida inicialmente por 
Bates e Granger no final da década de 1960 e desde então diversos estudos propuseram diferentes métodos de combinação.

A previsão combinada pode ser escrita como uma combinação linear de duas previsões não viesadas, conforme a Equação 2.

$$
F_{c}=w F_{1}+(1-w) F_{2}
$$

Onde $F_{c}$ é a previsão combinada pelas duas previsões individuais, $F_{1}$ e $F_{2}$, e $w$ e $(1-w)$ são os pesos designados para $F_{1}$ e $F_{2}$, respectivamente.

O método da variância mínima atribui maior peso à previsão que possui menores erros. Dessa forma, para calcular os pesos é utilizada a matriz de covariância dos erros das previsões individuais. Para encontrar o valor ótimo de $w$ da Equação 2 é preciso minimizar a variância dos erros da previsão combinada. O peso que minimiza essa variância é dado pela Equação 3.

$$
w^{*}=\frac{\left(\sigma_{2}^{2}-\rho \sigma_{1} \sigma_{2}\right)}{\left(\sigma_{1}^{2}+\sigma_{2}^{2}-2 \rho \sigma_{1} \sigma_{2}\right)}
$$

Onde $\sigma_{1}^{2}$ e $\sigma_{2}^{2}$ são as variâncias dos erros das previsões individuais e $\rho$ o coeficiente de correlação dos erros das previsões.

Este tipo de combinação utilizando duas previsões pode ser estendido para a combinação de $n$ previsões e Newbold e Granger (1974) concluíram que para erros não correlacionados, o termo $\rho$ poderia ser ignorado na estimação dos pesos, pois na prática ele teria pouca influência nos resultados. Desse modo a Equação 3 fica resumida como apresentado na Equação 4.

$$
w^{*}=\frac{\left(\sigma_{2}^{2}\right)}{\left(\sigma_{2}^{2}+\sigma_{1}^{2}\right)}
$$

Os pesos também podem ser estimados através de uma regressão linear, onde a variável resposta é a previsão combinada e as previsões individuais são as variáveis explicativas. Este método possui três variantes conforme o grau de flexibilidade permitida aos pesos. As variantes são expressas pelas Equações 8 a 10.

$$
\begin{array}{cr}
F_{c}=c+w_{1} F_{1}+w_{2} F_{2}+\varepsilon & \text { Equação 5 } \\
F_{c}=w_{1} F_{1}+w_{2} F_{2}+\varepsilon & \text { Equação 6 }
\end{array}
$$




$$
F_{c}=w_{1} F_{1}+\left(1-w_{1}\right) F_{2}+\varepsilon
$$

Equação 7

O modelo da Equação 5 contém uma constante (intercepto) que pode ser benéfica na correção de eventuais vieses das previsões individuais e não contém restrição sobre os pesos. O segundo e terceiro modelos (Equações 6 e 7) assumem que as previsões individuais são não viesadas. O modelo da Equação 7 possui uma restrição nos pesos que devem somar um. Neste artigo o método para combinação através de uma regressão linear a ser utilizado será o sem restrição nos pesos, podendo ser com ou sem constante de ajuste.

A técnica de combinação através da média aritmética é a mais comumente utilizada e a mais simples (SONG et al, 2009). Nesta técnica de combinação linear, diferentemente das outras duas apresentadas, o mesmo peso é atribuído a cada uma das previsões, conforme a Equação 8.

$$
F_{c}=0,5 F_{1}+0,5 F_{2} \quad \text { Equação } 8
$$

Já a combinação por média geométrica é bem menos utilizada que a média aritmética, sendo mais aplicada em situações especiais, principalmente no cenário econômico (PATTON; SHEPPARD, 2009). A vantagem dessa técnica de combinação é fornecer valores inferiores aos da média aritmética, proporcionado uma diminuição na estimativa da previsão, além de ser uma opção alternativa de método de combinação não linear. A Equação 9 expressa como obter a previsão combinada através da média geométrica.

$$
F_{c}=\sqrt{F_{1} \times F_{2}}
$$

Equação 9

Com ainda menos aplicações que a média geométrica, a média harmônica é outra forma não linear de combinar as previsões. Esse método também fornece previsões inferiores as obtidas pela média aritmética e é dada pela Equação 10.

$$
F_{c}=\frac{2 F_{1} \times F_{2}}{F_{1}+F_{2}}
$$

Equação 10

\section{Procedimentos Metodológicos}

Definiu-se inicialmente que seriam modeladas as demandas turísticas das três mais recentes sedes olímpicas até abril de 2016: Reino Unido (Londres, 2012), China (Pequim, 2008) e Grécia (Atenas, 2004). A variável escolhida como representativa da demanda turística foi o número de chegadas de turistas internacionais no país analisado que, de acordo com a 
metanálise de Peng, Song e Crouch (2014), é uma medida mais estável que as receitas turísticas, por exemplo. Assim, uma pessoa que faz várias viagens a um país durante um determinado período é contabilizada cada vez como uma nova chegada (WTO, 2015).

As informações acerca do número de chegadas foram obtidas diretamente das fontes oficiais dos governos dos países analisados, com exceção da China que não disponibilizou estas informações e, portanto, esta sede não pode ser analisada. Para a série do Reino Unido foram obtidas 391 observações mensais, desde janeiro de 1980 até julho de 2012 e para a série grega, 104 observações mensais desde janeiro de 1996 a agosto de 2004.

A modelagem de ambas as séries foi realizada com uma parte dos dados, sendo os últimos 12 meses retirados para posterior avaliação das previsões. Na modelagem do Reino Unido, a previsão foi realizada para julho de 2012, mês de início dos Jogos Olímpicos, que ocorreram entre 27 de julho a 12 de agosto de 2012.

As etapas para a análise de cada série temporal estão resumidas na Figura 1, sendo elas: i) etapa de modelagem individual e escolha do melhor modelo ARIMA (via critério de informação bayesiana normalizado - BIC Normalizado) e RNA (menor relação entre o erro quadrático médio das fases de treino e teste); ii) etapa de estimação das previsões individuais de cada modelo selecionado e das suas estimativas combinadas e, iii) etapa destinada à comparação, com auxílio de medidas de acurácia, das previsões individuais e combinadas, dentro e fora do período reservado para modelagem dos dados.

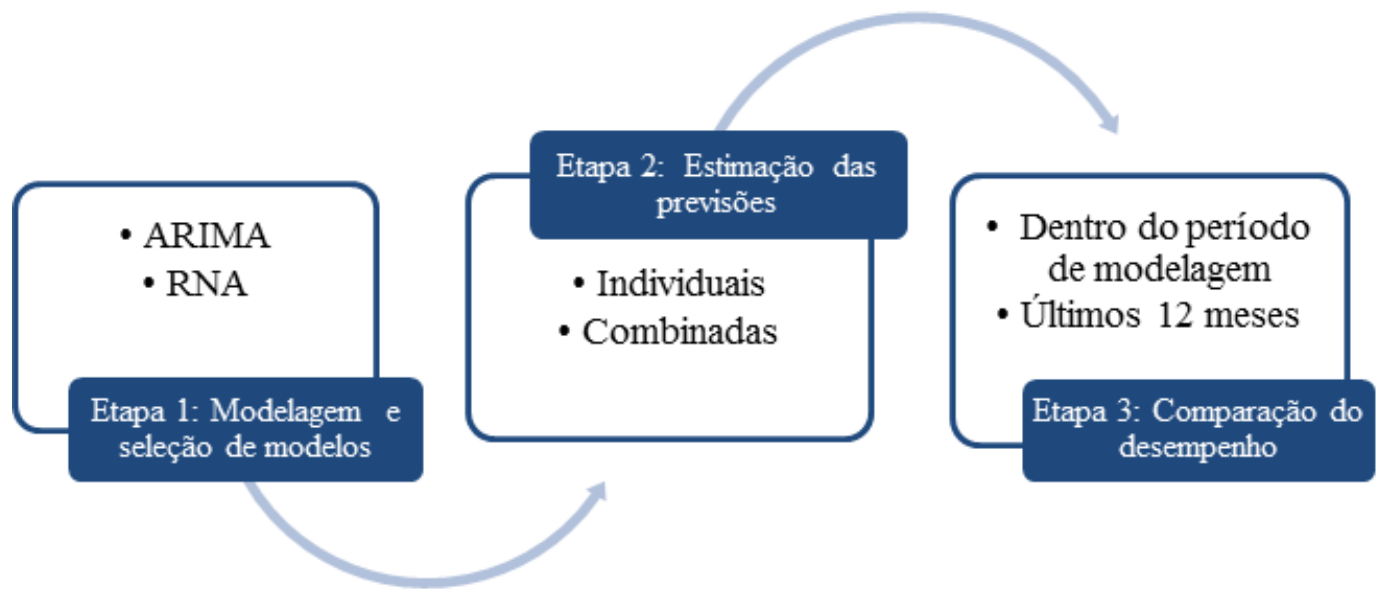

Figura 1: Etapas da análise de cada série de dados

Para a modelagem via metodologia de Box-Jenkins, alguns procedimentos de ajuste dos dados foram realizados, quando necessário, tais como: i) Transformação logarítmica: aplicada para 
estabilizar a variância; ii) verificação da estacionariedade através do teste ADF - (Augmented Dickley-Fuller); iii) operação da diferença para eliminar a tendência; iv) operação da diferença sazonal para eliminar a sazonalidade da série. Para cada modelo selecionado também foi utilizado o teste de Ljung-Box para verificar se os resíduos não estavam autocorrelacionados.

$\mathrm{Na}$ modelagem por RNA/MLP, os dados destinados à modelagem foram divididos aleatoriamente em dois conjuntos, sendo $70 \%$ dos dados destinados para aprendizagem ou padrão de treinamento e $30 \%$ destinados para teste. As redes geradas deveriam ter uma camada oculta com função de ativação não linear, como a tangente hiperbólica, e uma camada de saída com função de ativação do tipo linear (identidade), que segundo Fernandes et al. (2008) é a arquitetura mais adequada para esse tipo de dado. Quanto ao aprendizado, o algoritmo adotado foi o anteriormente exposto, retropropagação do erro, e essa fase se encerrava quando o erro quadrático médio da base de treino não apresentava mais diminuição, pois uma rede muito treinada tende a piorar sua capacidade de generalização.

Na Etapa 2 foram obtidas as previsões pelos modelos ARIMA e RNA selecionados e estas previsões foram combinadas de acordo com os cinco métodos sugeridos (variância mínima, regressão linear, médias aritmética, harmônica e geométrica) sendo que para o método de regressão linear foram consideradas as Equações 5 e 6, devido à flexibilidade quanto aos parâmetros.

A comparação das previsões obtidas na Etapa 3 foi realizada através das três principais medidas de acurácia encontradas na literatura, de forma igualitária, e estão resumidas no Quadro 1, sendo elas: MAPE (Mean Absolute Percentage Error), RMSE (Root Mean Square Error) e MAE (Mean Absolute Error). A primeira fornece uma medida percentual e as outras duas são avaliações de acurácia mensuradas na escala da variável utilizada.

Quadro 1: Medidas de acurácia utilizadas

\begin{tabular}{cc}
\hline Medida & $\frac{1}{n} \sum_{t=1}^{n}\left|\frac{A_{t}-F_{t}}{A_{t}}\right| \times 100$ \\
RMSE & $\sqrt{\frac{1}{n} \sum_{t=1}^{n}\left(A_{t}-F_{t}\right)^{2}}$ \\
MAE & $\frac{1}{n} \sum_{t=1}^{n}\left|A_{t}-F_{t}\right|$
\end{tabular}

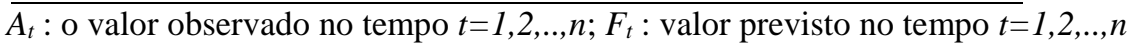


Os dados foram obtidos em planilha Excel. Inicialmente foi utilizado o software Gretl 2015 para verificação da suposição de estacionariedade e as demais análises (modelagem, adequação e cálculo das combinações de previsões) foram realizadas com auxílio do software SPSS v.21. Foi adotada significância de 5\% para os testes estatísticos.

\section{Resultados}

As Figuras 2 e 3 ilustram as séries históricas mensais do número de chegadas internacionais no Reino Unido e na Grécia, respectivamente, utilizadas para modelagem. Em ambas as séries, os meses com maior volume de chegadas foram julho e agosto, período de férias e verão na Europa e, nos meses de janeiro e fevereiro foram observadas as menores demandas. Em alguns anos, no Reino Unido, a demanda de julho chegou a ser o dobro da demanda observada em fevereiro e, na Grécia, em alguns anos o volume de turistas em agosto chegou a ser dez vezes superior à demanda observada em fevereiro.

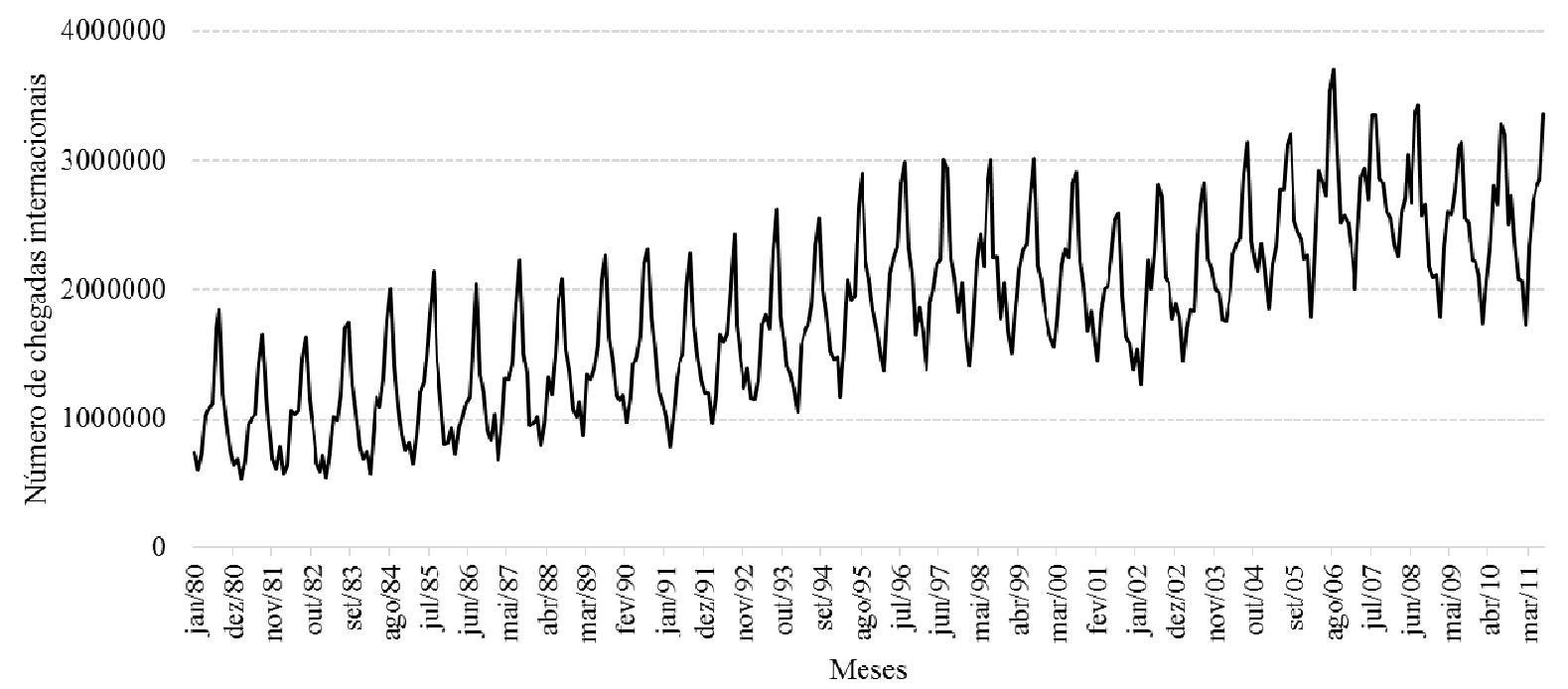

Figura 2: Número de chegadas internacionais no Reino Unido (jan/1980 - julho/2011) Fonte: Office for National Statistics (ONS) 


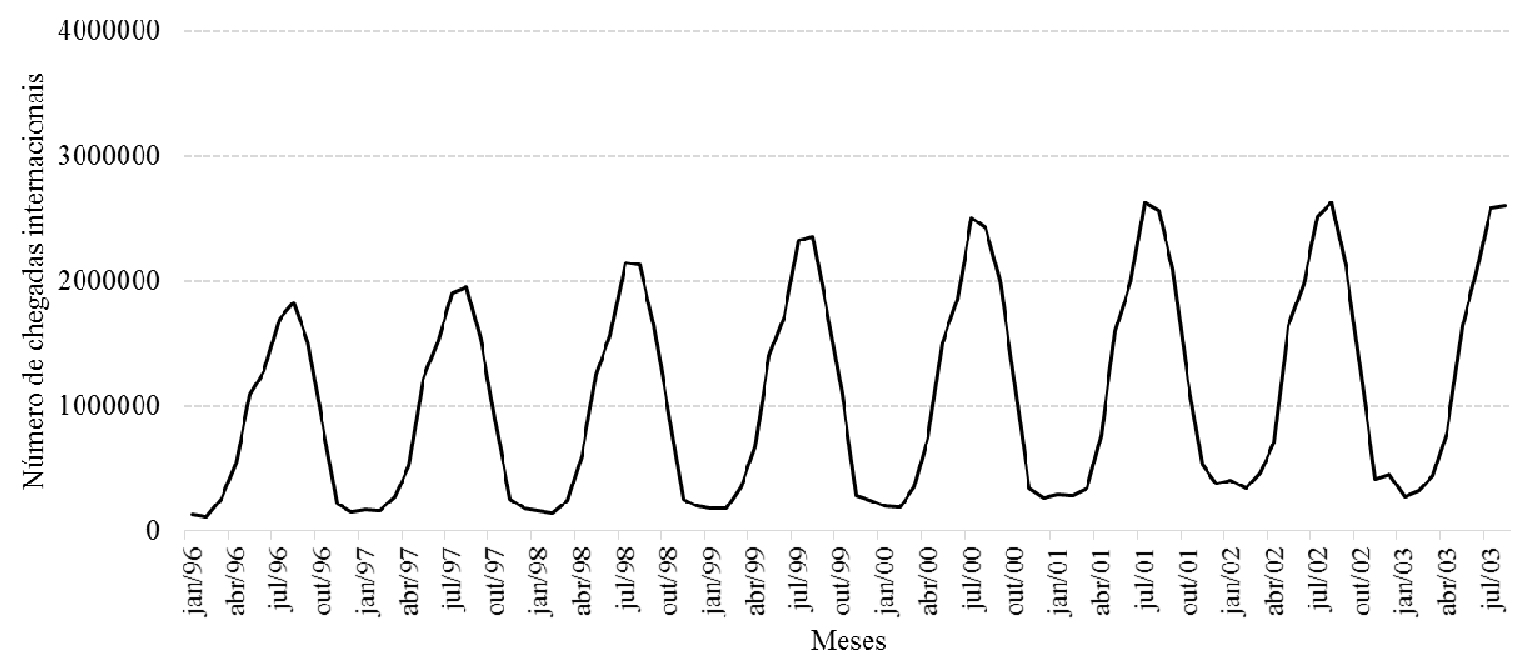

Figura 1: Número de chegadas internacionais na Grécia (jan/1994 - ago/2003)

Fonte: Hellenic Statistical Authority (ELSTAT)

Após a identificação da não estacionariedade e sazonalidade na série britânica, o modelo que obteve menor BIC, entre todos os modelos SARIMA analisados, foi o SARIMA $(0,1,1)(0,1,1)$. Para a série grega também foram observadas a não estacionaridade e a sazonalidade, além da não estabilidade da variância. O modelo com menor BIC utilizado para a modelagem dessa série foi o SARIMA $(1,1,1)(0,1,0)$. Para os modelos RNA definidos com uma camada oculta, com função de ativação tangente hiperbólica e uma camada de saída com função de ativação linear, foram testados de 2 a 12 neurônios na camada oculta, sendo que na série britânica o modelo com cinco neurônios obteve melhor resultado e na série grega o modelo com dois.

Na Tabela 2 estão discriminados os pesos atribuídos para cada previsão individual, de acordo com a técnica de combinação utilizada. Para as combinações obtidas através das médias aritmética, geométrica e harmônica foram dados pesos equivalentes as duas previsões individuais. Os métodos de variância mínima e regressão linear atribuíram pesos maiores às previsões obtidas pelo modelo RNA, especialmente na combinação via regressão linear. 
Tabela 1: Pesos utilizados em cada técnica de combinação

\begin{tabular}{lcccccc}
\hline \multirow{2}{*}{ Técnica de combinação } & \multicolumn{3}{c}{ Reino Unido } & \multicolumn{3}{c}{ Grécia } \\
& SARIMA & RNA & c & SARIMA & RNA & c \\
\hline Média Aritmética & 0,500 & 0,500 & - & 0,500 & 0,500 & - \\
Média Geométrica & 0,500 & 0,500 & - & 0,500 & 0,500 & - \\
Média Harmônica & 0,500 & 0,500 & - & 0,500 & 0,500 & - \\
Variância Mínima & 0,441 & 0,559 & - & 0,465 & 0,535 & - \\
Regressão Linear & $0,327^{*}$ & $0,671^{*}$ & $-6.955^{\text {ns }}$ & $0,348^{*}$ & $0,651^{*}$ & $-830^{\text {ns }}$ \\
\hline
\end{tabular}

A acurácia das predições estimadas pelos modelos SARIMA e RNA definidos, bem como a combinação dessas predições foi avaliada e está discriminada na Tabela 2. As predições do modelo RNA se mostraram mais acuradas que do modelo SARIMA, sob as três medidas avaliadas, em ambas as séries analisadas. Já na comparação somente entre os métodos de combinação de previsões, em ambas as séries a combinação via regressão linear foi a que apresentou melhor desempenho também sob as três medidas avaliadas. No geral, para as duas séries analisadas, todas as predições combinadas, independentemente do método, mostraramse mais precisas que as predições geradas pelos dois modelos individuais em ambas as três medidas.

Tabela 2: Medidas de acurácia dentro do período de modelagem

\begin{tabular}{lllll}
\hline \multirow{2}{*}{ Sede olímpica } & \multicolumn{3}{c}{ Modelos } & Medida \\
\cline { 3 - 5 } & SARIMA & $5,21 \%(7)$ & $117.360,69(7)$ & $91.326,30(7)$ \\
& RNA & $4,80 \%(6)$ & $104.447 .97(6)$ & $79.961,53(6)$ \\
Reino Unido & Média Aritmética & $4,48 \%(3)$ & $102.794,77(4)$ & $78.295,23(3)$ \\
$(379$ meses) & Média Geométrica & $4,48 \%(3)$ & $102.815,89(3)$ & $78.358,92(4)$ \\
& Média Harmônica & $4,48 \%(3)$ & $102.846,96(5)$ & $78.422,39(5)$ \\
& Variância Mínima & $4,47 \%(2)$ & $102.177,32(2)$ & $77.872,06(2)$ \\
& Regressão & $4,45 \%(\mathbf{1})$ & $101.669,68(\mathbf{1})$ & $77.356,08(\mathbf{1})$ \\
\hline \multirow{3}{*}{ Grécia } & SARIMA & $8,27 \%(7)$ & $74.736,64(7)$ & $55.693,19(7)$ \\
$(79$ meses) & RNA & $8,13 \%(6)$ & $68.775,82(6)$ & $49.837,42(6)$ \\
& Média Aritmética & $7,25 \%(5)$ & $55.095,08(3)$ & $44.165,35(5)$ \\
& Média Geométrica & $7,21 \%(3)$ & $54.830,44(5)$ & $44.067,98(4)$ \\
& Média Harmônica & $7,18 \%(\mathbf{1})$ & $54.609,75(4)$ & $43.971,60(3)$ \\
& Variância Mínima & $7,22 \%(4)$ & $54.533,17(2)$ & $43.780,50(2)$ \\
& Regressão & $7,18 \%(\mathbf{1})$ & $53.611,15(\mathbf{1})$ & $43.021,06(\mathbf{1})$ \\
\hline
\end{tabular}

Valores entre parênteses indicam a posição de cada técnica quanto ao desempenho obtido, de acordo com a medida de acurácia avaliada 
Diferentemente da Tabela 2 que apresenta um resumo da capacidade preditiva de cada técnica levando em conta todas as predições, nas Tabelas 3 e 4 as três medidas de acurácia foram calculadas utilizando os meses correspondentes a cada predição, nas séries britânica e grega, respectivamente. Para a série britânica, tanto as predições obtidas pelos modelos individuais quanto pela combinação via regressão, que obteve melhor desempenho na Tabela 2, apresentaram MAPE inferior a 10\%, independentemente do período, demonstrando alta acurácia. As predições obtidas pelo modelo SARIMA se mostraram mais precisas para os meses de setembro e dezembro, de acordo com as três medidas de acurácia. Unanimidade da acurácia também foi observada para as predições do modelo RNA para abril e junho. Já fevereiro, março, maio, julho e novembro foram melhor preditos pela combinação via regressão linear, também em consenso das medidas avaliadas. 


\section{TURISMO EM ANÁLISE}

Tabela 3: Acurácia das predições para a demanda britânica, de acordo com período

\begin{tabular}{|c|c|c|c|c|c|c|c|c|c|}
\hline \multirow{2}{*}{ Período } & \multicolumn{3}{|c|}{ MAPE } & \multicolumn{3}{|c|}{ RMSE } & \multicolumn{3}{|c|}{ MAE } \\
\hline & SARIMA & RNA & REG & SARIMA & RNA & REG & SARIMA & RNA & REG \\
\hline Janeiro & $6,64 \%(3)$ & $5,48 \%(2)$ & $5,15(\mathbf{1})$ & $106.944,5(3)$ & $86.427,4(2)$ & $78.695,6(\mathbf{1})$ & $86.728,3(3)$ & $71.374,8(2)$ & $65.914,4$ (1) \\
\hline Fevereiro & $6,57 \%(3)$ & $6,20 \%(2)$ & $5,69(\mathbf{1})$ & $97.959,2(3)$ & $97.788,1(2)$ & $91.570,7(\mathbf{1})$ & $81.738,8(3)$ & $78.658,6(2)$ & $72.657,3$ (1) \\
\hline Março & $5,52 \%(3)$ & $4,50 \%(2)$ & 4,09 (1) & $103.483,5(3)$ & $80.998,8(2)$ & $77.050,5(\mathbf{1})$ & $80.407,5(3)$ & $67.029,6(2)$ & 61.339,6 (1) \\
\hline Abril & $6,72 \%$ & $4,53 \%(\mathbf{1})$ & 4,89 (2) & $157.082,6(3)$ & $105.783,8(\mathbf{1})$ & $116.325,7$ (2) & $123.939,7(3)$ & $82.795,9$ (1) & $90.611,3(2)$ \\
\hline Maio & $4,84 \%(2)$ & $4,98 \%(3)$ & $4,57(\mathbf{1})$ & $122.986,0(3)$ & $115.085,5(2)$ & $110.632,5(\mathbf{1})$ & $94.575,9(3)$ & $91.322,7(2)$ & $86.856,4$ (1) \\
\hline Junho & $5,59 \%(3)$ & $3,85 \%(\mathbf{1})$ & $4,27(2)$ & $142.255,8(3)$ & $96.314,7$ (1) & $105.445,6(2)$ & $113.356,6(3)$ & $77.419,7$ (1) & $87.059,2(2)$ \\
\hline Julho & $3,38 \%(3)$ & $2,93 \%(2)$ & $2,51(1)$ & $108.075,2(3)$ & $104.947,1(2)$ & $96.669,1(1)$ & $85.632,1(3)$ & $78.347,3(2)$ & $68.661,4(1)$ \\
\hline Agosto & $3,81 \%(3)$ & $3,00 \%(\mathbf{1})$ & $3,01(2)$ & $115.172,4(3)$ & $104.669,4(2)$ & $101.224,9(\mathbf{1})$ & $99.534,6(3)$ & $77.998,6(2)$ & $77.939,2$ (1) \\
\hline Setembro & $3,52 \%(\mathbf{1})$ & $5,16 \%$ & $4,24(2)$ & $92.759,6(\mathbf{1})$ & $121.328,6(3)$ & $103.118,4(2)$ & $73.670,7$ (1) & $101.966,2(3)$ & $84.590,5$ (2) \\
\hline Outubro & $4,99 \%(3)$ & $4,17 \%(2)$ & $4,16(\mathbf{1})$ & $121.286,7(3)$ & $109.878,2(2)$ & $109.114,1$ (1) & $93.635,4(3)$ & $76.377,7$ (1) & $77.822,1(2)$ \\
\hline Novembro & $5,43 \%$ & $5,14 \%(2)$ & $4,80(\mathbf{1})$ & $109.040,3(2)$ & $109.056,8(3)$ & $103.891,4(\mathbf{1})$ & $83.316,3(3)$ & $80.716,6(2)$ & $74.984,0$ (1) \\
\hline Dezembro & $5,44 \%$ & $7,38 \%(3)$ & $6,29(2)$ & $125.572,4(\mathbf{1})$ & $137.784,1(3)$ & $128.604,7$ (2) & $91.674,0(\mathbf{1})$ & $104.523,2(3)$ & $95.202,0(2)$ \\
\hline
\end{tabular}

Valores entre parênteses indicam a posição de cada técnica quanto ao desempenho obtido em cada período, de acordo com a medida de acurácia avaliada. Em itálico o desempenho médio das predições realizadas para o mês em que os jogos olímpicos foram realizados no país. 
As medidas de acurácia de acordo com o mês de predição para a demanda grega são apresentadas na Tabela 4. Enquanto que durante o período de alta temporada, maio a outubro, o MAPE não ultrapassou 5\%, com exceção de outubro predito pelo modelo RNA, na baixa temporada, novembro a abril, o MAPE médio foi de 13,23\%, sendo observado 7,24\% para a demanda média de abril, obtida pela combinação via regressão, e 20,74\% na predição para janeiro via modelo SARIMA. Ainda, de acordo com as três medidas de acurácia, as predições obtidas pelo modelo SARIMA se mostraram mais precisas para os meses de fevereiro, outubro e dezembro. As demandas de junho, julho e novembro foram unanimemente melhor preditas pela modelagem RNA. Já maio e agosto foram melhor preditos pela combinação via regressão, também em consenso das três medidas adotadas. As predições para agosto, quando obtidas pela combinação linear, apresentaram MAPE inferior a 2\%.

A comparação da acurácia das previsões para o período de 12 meses, de forma que o último mês fosse o de realização dos Jogos Olímpicos está discriminada na Tabela 5. Em ambas as séries, as previsões individuais obtidas pelo modelo RNA foram mais acuradas que as geradas pelo modelo SARIMA. Na comparação somente entre os métodos de combinação de previsões, a combinação via regressão foi a mais acurada, para a série britânica, de acordo com MAPE e o MAE, enquanto que a combinação via média harmônica obteve o menor RMSE. Na série grega, o método de combinação via regressão foi o mais acurado ao analisar o MAPE e o segundo melhor nas outras medidas avaliadas.

$\mathrm{Na}$ avaliação geral, o pior desempenho apontado pelas três medidas de acurácia foi observado nas previsões geradas pelo modelo SARIMA, em ambas as séries. Na série britânica, as previsões via RNA apresentaram o melhor e o segundo melhor desempenho quanto ao MAPE e MAE, respectivamente, porém o segundo pior RMSE. Já as previsões combinadas via regressão estiveram sempre entre as melhores nas três medidas avaliadas. O desempenho das previsões gregas foi semelhante, onde o modelo RNA produziu os melhores resultados quanto ao RMSE e MAE e o segundo pior quanto ao MAPE, e as previsões combinadas pelo método de regressão linear estiveram sempre entre as melhores nas três medidas avaliadas. 
TURISMO EM ANÁLISE

Tabela 4: Acurácia das predições para a demanda grega, de acordo com período

\begin{tabular}{l|ccc|ccc|ccc}
\hline Período & \multicolumn{3}{|c|}{ MAPE } & & & RMSE & & MAE \\
& SARIMA & RNA & REG & SARIMA & RNA & REG & SARIMA & RNA & REG \\
\hline Janeiro & $20,74(3)$ & $17,44(\mathbf{1})$ & $18,48(2)$ & $82.576,2(3)$ & $56.484,3(2)$ & $55.995,0(\mathbf{1})$ & $57.098,4(3)$ & $45.122,5(\mathbf{1})$ & $49.110,2(2)$ \\
Fevereiro & $9,10(\mathbf{1})$ & $15,25(3)$ & $12,04(2)$ & $29.275,6(\mathbf{1})$ & $56.129,1(3)$ & $41.693,5(2)$ & $19.672,0(\mathbf{1})$ & $44.003,6(3)$ & $33.643,9(2)$ \\
Março & $15,38(3)$ & $12,29(\mathbf{1})$ & $13,15(2)$ & $60.968,1(3)$ & $54.089,1(2)$ & $51.287,1(\mathbf{1})$ & $55.430,4(3)$ & $41.569,8(\mathbf{1})$ & $45.667,5(2)$ \\
Abril & $9,83(3)$ & $8,26(2)$ & $7,24(\mathbf{1})$ & $84.524,3(3)$ & $63.648,0(\mathbf{1})$ & $63.999,7(2)$ & $69.023,7(3)$ & $57.616,0(2)$ & $49.826,8(\mathbf{1})$ \\
Maio & $2,89(3)$ & $2,22(2)$ & $1,77(\mathbf{1})$ & $50.659,3(3)$ & $39.914,2(2)$ & $32.132,5(\mathbf{1})$ & $42.362,7(3)$ & $31.801,9(2)$ & $26.323,4(\mathbf{1})$ \\
Junho & $2,72(3)$ & $1,40(\mathbf{1})$ & $1,92(2)$ & $63.796,5(3)$ & $33.882,6(\mathbf{1})$ & $38.059,4(2)$ & $52.539,7(3)$ & $25.192,5(\mathbf{1})$ & $35.811,1(2)$ \\
Julho & $3,41(3)$ & $1,40(\mathbf{1})$ & $1,64(2)$ & $110.057,4(3)$ & $41.868,9(\mathbf{1})$ & $48.837,1(2)$ & $81.301,0(3)$ & $34.917,4(\mathbf{1})$ & $40.219,6(2)$ \\
Agosto & $2,39(2)$ & $2,51(3)$ & $1,72(\mathbf{1})$ & $75.895,7(3)$ & $73.771,9(2)$ & $49.484,8(\mathbf{1})$ & $59.171,8(2)$ & $62.987,7(3)$ & $42.380,6(\mathbf{1})$ \\
Setembro & $3,45(3)$ & $1,61(\mathbf{1})$ & $1,67(2)$ & $80.273,7(3)$ & $40.452,3(2)$ & $39.617,7(\mathbf{1})$ & $69.356,1(3)$ & $29.925,4(\mathbf{1})$ & $32.098,7(2)$ \\
Outubro & $3,32(\mathbf{1})$ & $5,40(3)$ & $4,65(2)$ & $50.234,4(\mathbf{1})$ & $69.404,8(3)$ & $55.669,3(2)$ & $39.083,8(\mathbf{1})$ & $58.822,0(3)$ & $51.611,9(2)$ \\
Novembro & $18,09(3)$ & $14,16(\mathbf{1})$ & $14,62(2)$ & $104.707,7(3)$ & $55.228,5(\mathbf{1})$ & $65.192,2(2)$ & $76.219,7(3)$ & $51.639,6(\mathbf{1})$ & $57.114,5(2)$ \\
Dezembro & $8,01(\mathbf{1})$ & $13,21(3)$ & $10,89(2)$ & $34.599,9(\mathbf{1})$ & $59.703,3(3)$ & $50.352,1(2)$ & $28.226,7(\mathbf{1})$ & $46.259,8(3)$ & $38.788,5(2)$ \\
\hline
\end{tabular}

Valores entre parênteses indicam a posição de cada técnica quanto ao desempenho obtido em cada período, de acordo com a medida de acurácia avaliada. Em itálico o desempenho médio das predições realizadas para o mês em que os jogos olímpicos foram realizados no país. 
Tabela 5: Medidas de acurácia fora do período de modelagem - 12 meses

\begin{tabular}{llccc}
\hline \multirow{2}{*}{ Sede olímpica } & Modelos & \multicolumn{3}{c}{ Medida } \\
\cline { 3 - 4 } & & MAPE & RMSE & MAE \\
\hline \multirow{3}{*}{ Reino Unido } & $6,42 \%(7)$ & $175.019,33(7)$ & $160.587,21(7)$ \\
& RNA & $5,80 \%(\mathbf{1})$ & $173.544 .98(6)$ & $146.160,75(2)$ \\
& Média Aritmética & $6,00 \%(3)$ & $161.758,03(4)$ & $149.831,16(6)$ \\
& Média Harmônica & $5,97 \%(5)$ & $161.303,10(\mathbf{1})$ & $149.025,66(4)$ \\
& Variância Mínima & $5,95 \%(4)$ & $161.843,97(5)$ & $148.568,91(3)$ \\
& Regressão & $5,80 \%(1)$ & $161.609,59(3)$ & $144.870,21(\mathbf{1})$ \\
\hline \multirow{2}{*}{ Grécia } & ARIMA & $9,08 \%(7)$ & $130.684,88(7)$ & $104.059,76(7)$ \\
& RNA & $8,23 \%(6)$ & $95.710,96(\mathbf{1})$ & $77.403,30(\mathbf{1})$ \\
& Média Aritmética & $7,66 \%(5)$ & $108.653,92(6)$ & $86.444,63(6)$ \\
& Média Geométrica & $7,59 \%(4)$ & $108.515,03(5)$ & $86.051,61(5)$ \\
& Média Harmônica & $7,52 \%(2)$ & $108.428,07(4)$ & $85.665,08(4)$ \\
& Variância Mínima & $7,56 \%(3)$ & $107.405,95(3)$ & $85.216,48(3)$ \\
& Regressão & $7,21 \%(\mathbf{1})$ & $102.301,89(2)$ & $80.433,50(2)$
\end{tabular}

Valores entre parênteses indicam a posição de cada técnica quanto ao desempenho obtido, de acordo com a medida de acurácia avaliada

A previsão obtida pelo modelo SARIMA estimou 264.155 chegadas a mais para julho de 2012 que a previsão do modelo RNA. A previsão final obtida pela combinação por regressão linear foi de 3.197 .579 turistas (chegadas), ficando $1,25 \%$ acima do valor observado no período. Para a Grécia foram previstos 122.565 turistas a mais na previsão via ARIMA que na previsão RNA, para o mês de agosto de 2004. A previsão obtida pela combinação via regressão linear foi de 2.585.009, sendo superestimada em 5,83\%. Os resultados encontram-se na Tabela 6.

Tabela 1: Demandas turísticas observada e prevista para o mês de realização do evento

\begin{tabular}{lccc}
\hline Sede olímpica & Observada & Prevista & \multicolumn{2}{c}{ Erro (MAPE) } \\
\hline Reino Unido - julho/2012 & 3.158 .000 & 3.197 .579 & $39.580(1,25 \%)$ \\
Grécia - agosto/2004 & 2.442 .560 & 2.585 .009 & $142.443 \quad(5,83 \%)$ \\
\hline
\end{tabular}




\section{Discussões e Conclusões}

Este artigo avaliou a acurácia das previsões para a demanda turística de duas sedes olímpicas: Reino Unido, sede em 2012 e Grécia, sede em 2004. Para tanto, foi utilizado o maior número disponível de informações históricas do número mensal de chegadas nestes países. As previsões foram obtidas por dois modelos reconhecidamente robustos para realizar este tipo de análise (SARIMA e RNA) e combinadas por cinco métodos, através das médias aritmética, geométrica e harmônica, do método da variância mínima e através de regressão linear. A avaliação da acurácia se deu pelo posicionamento das previsões de acordo com três medidas amplamente utilizadas e igualmente ponderadas, tanto para as previsões amostradas para os dados utilizados na fase de modelagem quanto para as últimas 12 observações.

Constatou-se que os modelos SARIMA e RNA mais bem ajustados aos dados de ambas as séries também eram modelos com excelente capacidade preditiva, particularmente para a demanda britânica cujas previsões foram ainda mais acuradas que as previsões para a demanda grega. Para as previsões das observações utilizadas na modelagem, o MAPE não ultrapassou 8,27\% e para as últimas 12 observações, o maior MAPE foi de 9,08\%, ambos obtidos pela modelagem SARIMA na série Grega, sendo que a modelagem via RNA apresentou ainda menores valores. Para as previsões combinadas os resultados foram ainda melhores, onde o maior MAPE para as previsões amostradas foi de 7,18\% e 7,21\% para as previsões não amostradas, ambos da série grega.

$\mathrm{Na}$ avaliação geral, em ambas as séries analisadas, todas as previsões combinadas apresentaram melhor desempenho que a previsão obtida pela modelagem SARIMA, sob as três medidas de acurácia analisadas. Oh e Morzuch (2005) e Song et al (2009) encontram resultado semelhante onde o desempenho das previsões combinadas não foi pior que o desempenho do pior componente utilizado na combinação. A combinação via regressão, assim como neste estudo, também obteve melhor desempenho para a previsão das demandas da Austrália, Estados Unidos e Canadá no estudo de Shen, Li e Song (2011).

A alta acurácia observada na estimativa pontual para a demanda para os Jogos Olímpicos, além do método de combinação empregado, pode ter sido em função do efeito da sazonalidade apontado por Fourie e Santana-Gallego (2011). O continente europeu é a região do mundo mais visitada com cerca de 609 milhões de chegadas registradas em 2015 (WTO, 
2016). Não obstante, ao observar-se a demanda turística internacional das sedes analisadas, Reino Unido e Grécia são países que, sobretudo na alta temporada, apresentaram grande demanda turística internacional. Em virtude da realização dos Jogos Olímpicos justamente nesse período, nos dois países, onde, conforme a Tabela 3, as predições para os meses de julho e agosto eram mais precisas, tanto na modelagem ARIMA quanto RNA, não foi observado aumento do volume de chegadas. Contudo, ao realizar uma conjectura para os Jogos Olímpicos realizados no Brasil, onde agosto é um mês de baixa temporada, espera-se observar um grande impacto sobre o volume de chegadas de turistas internacionais.

O impacto na demanda devido à realização de um megaevento não foi observado em nenhuma das sedes analisadas uma vez que o evento ocorreu em um período de alta temporada, justamente onde os modelos escolhidos mostraram-se mais precisos. A escolha de boas modelagens individuais foi essencial para a obtenção de boas previsões e, através da combinação pelo método de regressão linear, o desempenho destas previsões foi melhorado, segundo as três medidas de acurácia avaliadas.

\section{Referências}

ARMSTRONG, J.S. Principles of forecasting: A handbook for researchers and practitioners. Springer Science \& Business Media, 2001.

BRAGA, A.P; CARVALHO, A.C.P.L.F; LUDERMIR, T.B. Redes neurais artificiais: teoria e aplicações. Rio de Janeiro, Livros Técnicos Científicos, 2007.

CLAVERIA, O; TORRA, S. Forecasting tourism demand to Catalonia: Neural networks vs. time series models. Economic Modelling, v.36, p.220-228, janeiro 2014.

CONSTANTINE, C.; PAPPALARDO, C. A hierarchical procedure for combination of forecasts. International Journal of Forecasting. v.26, p.725-743, 2010.

CROMPTON, J.L. Measuring the Economic Impact of Park and Recreation Services. Ashburn, VA: National Recreation and Park Association, 2010.

FERNANDES, P; TEIXEIRA, J; FERREIRA, J.M; AZEVEDO, S.G. Modelling Tourism Demand: A Comparative Study between Artificial Neural Networks and the Box-Jenkins Methodology. Romanian Journal of Economic Forecasting, v.9, n.3, p.30-50, 2008.

FOURIE, J; SANTANA-GALLEGO, M. The impact of mega-sport events on tourist arrivals. Tourism Management, v.32, n.6, p.1364 - 1370, 2011.

$\mathrm{GOH}, \mathrm{C}$; LAW, R. Modeling and forecasting tourism demand for arrivals with stochastic nonstationary seasonality and intervention. Tourism Management, v.23, n.5, p.499-510, 2002.

GOLDSCHMIDT, R., PASSOS, E. Data mining: Um guia prático. Rio de Janeiro: Editora Campus, 2005. 
HALL, C.M. Hallmark tourist events: Impacts, management and planning. London: Bellhaven Press. 1992.

HALL, C.M. Urban entrepreneurship, corporate interests and sports mega-events: the thin policies of competitiveness within the hard outcomes of neoliberalism. The Sociological Review, v.54, n. s2, p. 59-70, December 2006.

HAYKIN, S. Redes neurais: Princípios e prática. Bookman, $2^{\mathrm{a}}$ Ed, 2001.

HORNE, J; MANZENREITER, W. An introduction to the sociology of sports megaevents. The Sociological Review, v.54, n.2, p.1-24, December 2006.

KON, S.C; TURNER, W.L. Neural network forecasting of tourism demand, Tourism Economics, v.11, n.3, p.301-328, 2005.

KUTNER, M, H; NACHTSHEIM, C.J; NETER, J; LI, W. Applied Linear Statistical Models,

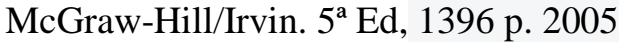

LONDON ASSEMBLY. Legacy for London? Assessing the legacy of the Olympic Games and Paralympic Games. Greater London Authority, 2007.

MORETTIN, P.A; TOLOI, C.M. Análise de Séries Temporais. São Paulo: Editora Edgard Blücher,. 531 p. 2006

MOURA, F.A; MONTINI, A.A. Modelagem da Demanda Turística Internacional para o Estado de São Paulo. Sociedade, Contabilidade e Gestão, v.5, n.2, jul/dez 2010.

NEWBOLD, P., GRANGER, C, W, J. Experience with forecasting univariate time series and the combination of forecasts. Journal of the Royal Statistical Society, Series A, v.137, n.2, p.131-146, 1974.

OH, C; MORZUCH, B.J. Evaluating Time-Series Models to Forecast the Demand for Tourism in Singapore. Journal of Travel Research, v.43, n.4, p.404-413, 2005.

PAI, A.P.F; LIN, B.K.P; LIN, C.C.S; CHANG, P.T. Time series forecasting by a seasonal support vector regression model. Expert Systems with Applications, v.37, n.6, p.4261-4265, 2010.

PATTON, A.J; SHEPPARD, K. Optimal combinations of realized volatility estimators. International Journal of Forecasting, v.25, n.2, p. 218-238, 2009.

PENG, B; SONG, H; CROUCH, G.I. A meta-analysis of international tourism demand forecasting and implications for practice. Tourism Management, v.45, p.181-193, 2014.

ROCHE, M. Mega events and urban policy. Annals of tourism research, v.21, n.1, p.1-19, 1994.

SANTOVITO, T.C. A copa do mundo 2006: megaevento esportivo como atração turística, instrumento de comunicação e interação entre os povos. Comunicação \& Inovação, v7, n.13, 2010.

SHEN, S; LI, G; SONG, H. Combination forecasts of International tourism demand. Annals of Tourism Research, v.38, n. 1, p. 72-89, 2011.

SOLBERG, H.A; PREUSS, H. Major Sport Events and Long-Term Tourism Impacts. Journal of Sport Management, v. 21, n.2, p.213-234, 2007.

SONG, H; HYNDMAN, R.J. Tourism forecasting: An introduction. International Journal of Forecasting, v.27, n.3, p.817-821, 2011.

SONG, H.; LI, G. Tourism demand modelling and forecasting - A review of recent research. Tourism Management, v.29, n.2, p.203-220, 2008.

SONG, H; WITT, S.F; WONG, K.F; WU, D.C. An empirical study of forecast combination in tourism. Journal of Hospitality \& Tourism Research, v.33, n.1, p.3-29, 2009. 
STEKLER, H.O. Improving Our Ability to Predict the Unusual Event. International Journal of Forecasting, v.19, n.2, p.161-63, 2003.

TAVARES, O. Megaeventos esportivos. Movimento (ESEF/UFRGS), v.17, n.3, p.11-35, 2011.

TIDESWELL, C; MULES, T; FAULKNER, B. An Integrative Approach to Tourism Forecasting: A Glance in the Rearview Mirror. Journal of Travel Research, v.40, n.2, p.162-171, 2001.

TSENG, H; MA, Z; CHOU, L. An Author-based Citation and Co-citation Analysis on Tourism Research. Asia Pacific Management Review, v.15, n.4, p.585-600, 2010.

WTO (World Tourism Organization). Methodological Notes, Disponível em: http://www.unwto.org/facts/menu.html. Acesso em: dez. 2015. 2015

World Tourism Barometer. v.14, n.5, 2016 Disponível em: http://www.unwto.org/facts/menu.html. Acesso em: abril. 2016. 2016

ZHANG, G; PATUWO, B.E; HU, M.Y. Forecasting with artificial neural networks: The state of the art. International Journal of Forecasting, v.14, n.1, p.35-62, March 1998.

Recebido: $25 / 01 / 2016$ ( $1^{\text {a }}$ versão) $19 / 04 / 2016$ ( $2^{\mathrm{a}}$ versão)

Aprovado: 11/04/2016 